\section{Rate of Growth of the Common Starfish, Asterias rubens.}

In the course of a study of the growths on the buoys and beacons in Liverpool Bay marking the entrance to the Mersey Estuary, young Asterias rubens have in nearly all cases been found clinging to the undersides of those structures. There is no doubt that these starfishes have settled as larvæ in this position and have grown in situ by feeding on coexisting mussels (Mytilus edulis), which have always been found in abundance. As definite observations on the rate of growth of the common starfish are necessarily rare and difficult to obtain, the following are of interest.

On May 30, 1930, the black beacon $Q 7$ from the Queen's Channel was dry-docked and examined, and found to be carrying a large number of young Asterias rubens. About 1800 of these were collected, preserved in the laboratory, and afterwards measured to give the graph shown in Fig. 1. The measurement adopted

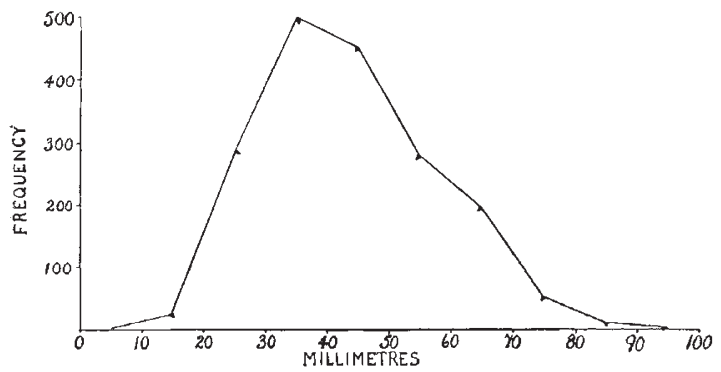

Fig. 1.- Size-frequency in $10 \mathrm{~mm}$. groups of 1805 Asterias rubens (aged not more than 1 year) from the black beacon Q7, Queen's Channel, Liverpool Bay, May 30, 1930.

to give a criterion of size is the length of the straight line joining the tips of alternate arms. The modal value in Fig. 1 is nearly $4.0 \mathrm{~cm}$., while size ranges between $7 \mathrm{~mm}$. and $9.4 \mathrm{~cm}$., and the mean value is $4.2 \mathrm{~cm}$. In life these specimens would measure in repose about $5 \mathrm{~mm}$. more on the average. As the buoy $Q 7$ was placed on station on April 3, 1929, the greatest age of these Asterias is about 13 months. The actual age is, however, rather less. Post-larval Asterias of only a few millimetres were obtained in 1930 on a buoy (C8 black) on July 25 -and rather larger sizes in great quantities on other buoys at a later date-thereby proving that settlement occurs in this stage and giving also an indication of the date of settlement.

If post-larvæ be assumed to settle in general on buoys from about June onwards, then it is seen that a population of Asterias may attain a maximum size of about $10 \mathrm{~cm}$. and a mean of $4-5 \mathrm{~cm}$. in less than one year. But as Asterias probably spawns round about April in this locality, the actual age (from the time of fertilisation ) of these small starfishes is approximately one year. It is an extremely interesting fact that minute post-larval Mytilus were obtained on another buoy ( $Q 3$ black) on June 27,1930 , at just about the right time to serve as food for the growing baby Asterias. The latter have not been observed actually eating the post-larval mussels, but there can be little doubt that this is the source of their sustenance. Young mussels were probably also largely the food of Echinus miliaris taken from the bottom of the Bar lightship along with $15 \mathrm{~cm}$. Asterias rubens, large mussels, medium Actinoloba dianthus and other forms, also on June 27, 1930. These Echinus, it may be noted, were mostly the long-spined variety, and were similar in this respect and in size to those obtained on the coal hulk London City (see Nature, 111, p. I46; 1923). As these sea-urchins could only attain access to the bottom of ships by the settlement of larval forms, and as this lightship was put out on Nov. 22, 1927, their age, as well as that of the larger Asterias, is not more than two years.

We are greatly indebted to Capt. Mace and Mr. A. L. Hulme, of the Mersey Docks and Harbour Board, who kindly supplied information regarding the records of the buoys mentioned above. J. H. ORTON.

The University, Liverpool, Aug. 28. J. H. Fraser.

\section{Depreciated Morphology.}

In a recent review (NATüRE, Sept. 6, p. 341), Prof. Elliot Smith reproves at some length an anonymous group of contemporary biologists whose attitude towards morphology is one of ill-concealed contempt. Escaping the discipline which alone attends the laborious drudgery of morphological research, they pour contempt on that field of biology which, in the past, has yielded all our richest fruits. Few biologists will read Prof. Elliot Smith's remarks unmoved. Some will learn, for the first time, that there is a race of up. starts-presumably experimental biologists-who not only ignore, but also despise, the foundations of their own beliefs. Others-perhaps no insignificant minority-will learn with dismay of the great gulf which protects the true morphologist from the taint of experimental corruption.

I venture to think that the picture is not quite so dark as Prof. Elliot Smith has painted it. Whether we use a macerating pot or an X-ray for the study of animal form, the goal remains the same - to show how the component parts of an animal (whether they be bones or molecules) are so shaped and so orientated to one another as to form a living organism capable of undergoing evolutionary change. To this end the morphologist (in the classical sense) has contributed, and is continuing to contribute, a more complete record of correlated facts than his younger colleagues in experimental laboratories ean hope to do for many years to come. Nevertheless, the final goal will not be reached by those who restrict their conceptions of animal life to the facts revealed by a scalpel and a microtome, or by those who ignore all knowledge of the anatomical sciences. Until we can add to such facts as are described in Prof. Goodrich's distinguished volume a knowledge of the form and mechanism concealed within a muscle fibre and a gamete, the theories of the evolution of the vertebrate skeleton will neces. sarily remain vague and unsatisfying to certain types of mind.

Facts of real biological significance are drawn from an ever-widening field, and there is an inevitable tendency to specialise in apparently unrelated territories. To some extent this is inevitable, but whether we regard an organism as an intricate piece of molecular machinery or whether we prefer to examine the brain with a hand lens, it scarcely seems necessary to allow our predilection for one or other point of view to imply a negation or an implied criticism of the other. It is just as inconsistent to ignore the morphological significance of experimental data as it is to study the behaviour of an organism without reference to its form or evolutionary history. If experimental biologists are too fond of 'looping the loop', it is equally true that morphologists are not disinclined to creep about on all-fours.

It is to be hoped that experimental biology will never be regarded as the antithesis to morphology. There is no intrinsic virtue in experiment-it is solely an additional weapon of biological armament. The very name 'experimental' is a misnomer and might well be replaced by 'analytical', for this at least indicates an attitude of mind of those who attempt to analyse 